Practice Reflections

\title{
Utilising a virtual community to practice Community Work theory during COVID-19 lockdown in South Africa
}

\section{Elmien Claassens ${ }^{1}$}

\begin{abstract}
In this practice note, I highlight the challenges practice lecturers overcame during a national lockdown midst the COVID-19 pandemic in South Africa. They continued with online teaching and learning, teaching community work to students by using a fictitious, virtual community which they created to enable students to apply the theoretical knowledge on community work in the practice module. I share the practical application on how students were able to 'do' community work in a virtual community during the practice module.
\end{abstract}

Keywords: virtual community; fictitious community; online teaching and learning; community work; practice learning; COVID-19; social work; South Africa

1. Practice Lecturer, Department of Social Work and Criminology, University of Pretoria, Pretoria, South Africa

Address for correspondence: elmien.claassens@up.ac.za

Date of first (online) publication: 22nd January 2021

Note: Ngampela I was guided on the translation of this word by an African who is a speaker of the Isizulu language. 


\section{Introduction}

I had twenty years experience in community development in the non-profit sector before I started as a part-time practice lecturer in social work at the University of Pretoria (UP) in March 2017. As practice lecturers we oversee the students' practice modules for the whole year in each of the different year groups. For 2020, I am involved with the second year students as well as the final (4th) year students as a practice lecturer.

In our second year social work curriculum, we emphasise community work as a method as well as community-based group work. Second-year students are enrolled for a theory module on Community Work, and then in our Practice module we go into the actual 'doing' of what they have learnt in theory. In the second year Practice Module, we have in-depth exposure to community work and allow the students to experience the process of community work in action, including doing the situational analysis, interacting with community members in critical dialogues, identifying possible projects together with the community, executing the project as well as making sense and communicating what they have successfully implemented as well as the way forward after implementation of the project.

In normal teaching and learning circumstances the synergy between the theory module and practice works very well and it is evident that students are gaining experience on what they have learnt in the theory module on Community Work.

However, in 2020, with the global COVID-19 pandemic, the practice lecturers were faced with many challenges, especially in the online teaching and learning environment, one of which was the practical component of Community Work in our module. Towards the end of March 2020, just after students completed the theory module on Community Work, our South-African government announced a national lockdown, which inevitably meant that universities were subsequently closed down. Our institution proactively started a process to assist students with devices, and the government on behalf of university students negotiated access to data with different service providers nationally. This process meant that all students were able to continue with online teaching and learning, and within a couple of weeks, our online teaching and learning started.

Due to the practical nature of our module we were inevitably faced with many challenges as well as the fact that all communities nationally

139 J. of Practice Teaching \& Learning 17(3), pp.138-143. @ wE-b 
were placed in lockdown - meaning that students were unable to even use their own communities as a point of reference, seeing that they were also in lockdown in those communities. This dilemma forced us to think completely out of the 'box' and the process we followed for so many years as practice lecturers. O'Leary \& Tsui (2020:1) quoted an interview with Rebecca Solnit that observes: 'Disasters shake things loose. And the things that we regarded as fixed and unchangeable can suddenly be changed.' This could not have been truer than for us as a second-year committee.

Our reality was that we had to find a community to which we could refer students, with the aim of still giving them exposure to community work. An actual physical community was not possible, as we were in lockdown ourselves as lecturers and students were scattered all over South-Africa in different communities. These communities were all unique and their point of reference would not have been the same and were all in lockdown. While being busy with the preparation for the online teaching and learning, I was contemplating the use of photographs for that specific class discussion to highlight the value of observation when social workers are working in communities. That was the moment I realized that we could create our own virtual fictitious community by making our own video from different photos and material we could find. Ngampela, the fictitious virtual community was born beginning of April 2020. Ngampela means 'virtual' in Isizulu, one of the eleven official languages in South Africa. A friend of mine helped me to find the Isizulu word for virtual and Ngampela was his suggestion stemming from traditional Isizulu language.

Virtual being defined by the Cambridge Online Dictionary as 'something that can be seen using a computer and therefore without going anywhere or talking to anyone'. During all the challenges with lockdown virtual seems like the 'thing' that could enable us to continue with our online community work process with students. Significant research suggests that virtual communities hold some benefits as learning communities and communities of practice for future social workers, mainly as a means of delivering experiential learning and traditional classroom content (Greene, 2017, p.15). Together as colleagues we brainstormed the idea, and this 'strange' new concept of a fictitious, virtual community very soon came together as if it was a community we knew for many years and we could visualise it clearly. In our committee of practice lecturers, I was the one with the most (which was still very limited) computer designing skills so I offered to put it all together in a video. Working remotely from home, we did not have access to as much IT support, so we had to work with that

140 J. of Practice Teaching \& Learning 17(3), pp.138-143. @ wEb 
which was at our disposal.

After 8 weeks of online teaching and learning, Ngampela is now part of our point of reference for our weekly class discussions and we were able to help students to apply the community work theory to this created virtual, fictitious community. Stemming from their theory classes, students were required to apply the Cycle Model from Ledwith (2016, p.152), stage by stage. In the first stage of Being, students were able to gain new insight on Ngampela, such as noticing dangerous conditions like no access to clean water in the community, and the realities around the COVID-19 pandemic, which brought health care services to the community but only during the pandemic. So, all injustices in Ngampela were observed by students in smaller groups during the weekly class discussions.

As mentioned by Reamer, (2019:423) some of the best practices learned from online teaching, includes the notion of creating a supportive online community, which aims to minimize the isolation students were feeling. This author mentioned a practical suggestion to design assignments that required students to communicate and engage with each other through an online platform. This was especially true for our students during lockdown and we therefor arranged our students into smaller groups to work on their Community Profile Assignment, as applied to the Ngampela community. Students were able to do this assignment in their small groups, using the Discussion Boards on our ClickUP portal as made available by our institution. ClickUP is the Learner Management System used by the University of Pretoria and were zero-rated for use of data, so all students were able to have access and participate. This inclusive process of online teaching and learning was the only way of reaching every student where they found themselves during lockdown.

Furthermore, in the second stage of Problematising, students were then able to capture situations from the Ngampela community that they felt was relevant to the local people. They also had the opportunity to put the problems identified in context with trends in our country as well as statistics available. We then finished the third stage of Conscientisation answering the question on 'What shall we do about it?' and it called for a plan of action, capable of change. This allowed students in their smaller groups to have critical dialogues on possible plans for the Ngampela community that could address some of the injustices they have observed in the virtual community. In the fourth stage students will get the exposure to engage in action with the wider community and make links with possible campaigns or projects they could implement in the community.

141 J. of Practice Teaching \& Learning 17(3), pp.138-143. @ wE-b 
They will draft an action plan as a small group, together with writing funding letters to possible donors, and at the end of this stage they should have a fictitious project proposed to the practice lecturers. In the last two stages, the students will be required to make sense (stage 5) and turn their experience into meaning and find a deeper understanding of what they have experienced. This step is to continue to identify another cycle of development and start to plan the next stage. Finally, in stage six students will be offered an opportunity to communicate their new knowledge that was co-created by the participants so that others can learn from their experience. This is necessary to 'contribute to an increasing body of community development knowledge' (Ledwith, 2016, p.154), and in doing so it keeps our 'community development critical and at the forefront of social justice practice'.

\section{Conclusion}

At the time of writing this reflective practice note, we are still on the journey of online teaching and learning, and our students have still not returned to campus for contact classes. At the start of this process of adapting our curriculum to an online platform only, we had to dig deep for enough creativity and innovation, to not stay stuck with only what we have known as our norm for many years. In reflecting back over this period, I have learnt that social work educators have shown tremendous resilience during trying and uncertain times. Students already provided mid-year feedback that they are enjoying the virtual community and even more so, thankful that they are able to continue with their practice curriculum, even during lockdown.

Lastly, I leave you with this thought: We should never underestimate how uncertain times can unlock opportunities for learning, for both social work educators and students.

\section{References}

Cambridge Online Dictionary. Online at https://dictionary.cambridge.org/ dictionary/english/virtual [accessed on 01.07.20]

142 J. of Practice Teaching \& Learning 17(3), pp.138-143. @ wE-b 
Greene, M.P. (2017). Virtual communities of practice. Macro Practice, Social Work Practice Profession. Online at https://oxfordre.com/socialwork/view/10.1093/ acrefore/9780199975839.001.0001/acrefore-9780199975839-e-1068 [accessed on 30.06.20] DOI: 10.1093/acrefore/9780199975839.013.1068

Ledwith, M. (2017). Review of Community Development in Action: Putting Freire into practice. Community Development Journal, 52, 1, 217-219

O'Leary, P. \& Tsui, M. (2020). Social work's role during and after the pandemic: Keeping vigilant and hopeful on human rights. International Social Work, 63, 4, 417-418, DOI: 10.1177/0020872820936430

Reamer, F.G. (2019). Social work education in a digital world: Technology standards for education and practice. Journal of Social Work Education, 55, 3, 420-432, DOI: 10.1080/10437797.2019.1567412

143 J. of Practice Teaching \& Learning 17(3), pp.138-143. @ w\&bb 